\title{
Cortical Synaptic Transmission and Plasticity in Acute Liver Failure Are Decreased by Presynaptic Events
}

\author{
Mariusz Popek $^{1}$ - Bartosz Bobula ${ }^{2}$ - Joanna Sowa ${ }^{2}$ - Grzegorz Hess ${ }^{2} \cdot$ Rafal Polowy $^{3}$. \\ Robert Kuba Filipkowski ${ }^{3}$ - Malgorzata Frontczak-Baniewicz ${ }^{4}$ - Barbara Zabłocka ${ }^{5}$. \\ Jan Albrecht ${ }^{1}$ - Magdalena Zielińska ${ }^{1}$ (D)
}

Received: 19 September 2016 / Accepted: 28 December 2016/Published online: 23 January 2017

(C) The Author(s) 2017. This article is published with open access at Springerlink.com

\begin{abstract}
Neurological symptoms of acute liver failure (ALF) reflect decreased excitatory transmission, but the status of ALFaffected excitatory synapse has not been characterized in detail. We studied the effects of ALF in mouse on synaptic transmission and plasticity ex vivo and its relation to distribution of (i) synaptic vesicles (sv) and (ii) functional synaptic proteins within the synapse. ALF-competent neurological and biochemical changes were induced in mice with azoxymethane (AOM). Electrophysiological characteristics (long-term potentiation, whole-cell recording) as well as synapse ultrastructure were evaluated in the cerebral cortex. Also, sv were quantified in the presynaptic zone by electron microscopy. Finally, presynaptic proteins in the membrane-enriched (P2) and cytosolic (S2) fractions of cortical homogenates were quantitated by Western blot. Slices derived from symptomatic AOM mice presented a set of electrophysiological correlates of impaired transmitter release including decreased field potentials (FPs), increased paired-pulse
\end{abstract}

Magdalena Zielińska

mzielinska@imdik.pan.pl

1 Department of Neurotoxicology, Mossakowski Medical Research Centre, Polish Academy of Sciences, Pawińskiego $5 \mathrm{St}$, 02-106 Warsaw, Poland

2 Department of Physiology, Institute of Pharmacology, Polish Academy of Sciences, Smetna 12 St, 31-343 Cracow, Poland

3 Behavior and Metabolism Research Laboratory, Mossakowski Medical Research Centre, Polish Academy of Sciences, Pawińskiego 5 St, 02-106 Warsaw, Poland

4 Electron Microscopy Platform, Mossakowski Medical Research Centre Polish Academy of Sciences, Pawińskiego $5 \mathrm{St}$, 02-106 Warsaw, Poland

5 Molecular Biology Unit, Mossakowski Medical Research Centre, Polish Academy of Sciences, Pawińskiego 5 St, 02-106 Warsaw, Poland facilitation (PPF), and decreased frequency of spontaneous and miniature excitatory postsynaptic currents (sEPSCs/mEPSCs) accompanied by reduction of the spontaneous transmitter release-driving protein, vtilA. Additionally, an increased number of sv per synapse and a decrease of $\mathrm{P} 2$ content and/or $\mathrm{P} 2 / \mathrm{S} 2$ ratio for sv-associated proteins, i.e. synaptophysin, synaptotagmin, and Munc18-1, were found, in spite of decreased content of the sv-docking protein, syntaxin-1. Slices from AOM-treated asymptomatic mice showed impaired long-term potentiation (LTP) and increased PPF but no changes in transmitter release or presynaptic protein composition. Our findings demonstrate that a decrease of synaptic transmission in symptomatic ALF is associated with inefficient recruitment of sv proteins and/or impaired sv trafficking to transmitter release sites.

Keywords Acute liver failure · Presynaptic events · Neurotransmission

\section{Introduction}

Neuropsychiatric symptoms of acute or chronic liver failure (ALF or CLF), collectively defined as hepatic encephalopathy (HE), are associated with a decline of excitatory neurotransmission [1-3]. Present knowledge of the electrophysiological and molecular correlates of ALF- or CLF-affected synapse is confined mostly to the postsynaptic events related to altered Glu receptor-mediated signaling pathways [4] and/or synaptic plasticity, i.e., long-term potentiation (LTP) and LTD [5], while the status of the presynaptic region involved in neurotransmitter release has remained unattended. A few earlier reports have dealt with alterations in the synaptic events in brain preparations treated with ammonia, which is a major neurotoxin implicated in $\mathrm{HE}$ [6], emphasizing the role of postsynaptic changes [7-10]. However, the observations were confined to short-term effects (seconds to minutes), which 
cannot be considered representative for the progression of ALF symptoms lasting for hours to weeks. In this study, therefore, we address the question whether and to what extent ALF disturbs the functional and structural integrity of the presynaptic neurotransmitter release machinery in addition to postsynaptic changes. We therefore measured expression and distribution of presynaptic proteins including (i) the integral vesicle proteins synaptophysin and synaptotagmin; (ii) a member of the Sec1/Munc18-like protein family Munc-18-1; (iii) an integrated SNARE protein syntaxin-1; and (iv) vt1 interactor 1a (vtila) protein, which characterizes vesicles driving spontaneous release [11-13]. The response of presynaptic proteins to ALF was compared to that of the constituents of the postsynaptic complex active in signal transduction, NMDA subunit NR1, PSD95, and the neuronal form of nitric oxide synthase (nNOS). The analysis was carried out in mice in which ALF was induced with a hepatotoxin, azoxymethane (AOM), and was preceded by thorough behavioral, biochemical, and neurophysiological characterization of the model. The results presented in Table 1 and Figs. 1 and 2 confirm and extend the findings by others that the mouse AOM model is a valid model of acute HE in humans [14-16].

Cerebral cortical slices derived from AOM-treated asymptomatic and symptomatic mice were subjected to the electrophysiological analysis of field potentials (FPs), including paired-pulse facilitation (PPF) ratio, parameters characterizing excitability of pyramidal neurons, and spontaneous excitatory postsynaptic currents (sEPSCs) as well as miniature excitatory postsynaptic currents (mEPSCs).

Growing evidence that liver failure affects synaptic plasticity and that Glu release plays a crucial role in driving the postsynaptic events [17] prompted us to assess long-lasting activity-dependent changes in synaptic efficiency, known as LTP. LTP underlies multiple forms of synaptic plasticity in the brain [18]. Analysis of the morphological and biochemical status of the synapse focused on the neurotransmitter release apparatus. Ultrastructural assessment of the presynaptic zone comprised the size and content of sv. Next, we examined the content and distribution between the cytosolic- and membrane-enriched compartments of the cerebral frontal

Table 1 Increased concentration of cytokines, ammonia, and activity of liver damage marker enzymes in serum of control and AOM mice

\begin{tabular}{lll}
\hline & Con & AOM \\
\hline IL-6 $(\mathrm{pg} / \mathrm{ml})$ & $10.0 \pm 2.2$ & $214.5 \pm 34.5^{*}$ \\
TNF- $\alpha(\mathrm{pg} / \mathrm{ml})$ & $3.1 \pm 0.2$ & $14.7 \pm 1.8^{*}$ \\
AST $(\mathrm{IU} / \mathrm{I})$ & $172.4 \pm 30.6$ & $805.4 \pm 92.2^{*}$ \\
ALT $(\mathrm{IU} / \mathrm{I})$ & $46.5 \pm 6.1$ & $559.0 \pm 52.8^{*}$ \\
Ammonia $(\mathrm{mg} / \mathrm{ml})$ & $0.0052 \pm 0.0011$ & $0.0140 \pm 0.0010^{*}$ \\
\hline
\end{tabular}

$* p<0.05$ vs. Con; $n=6$
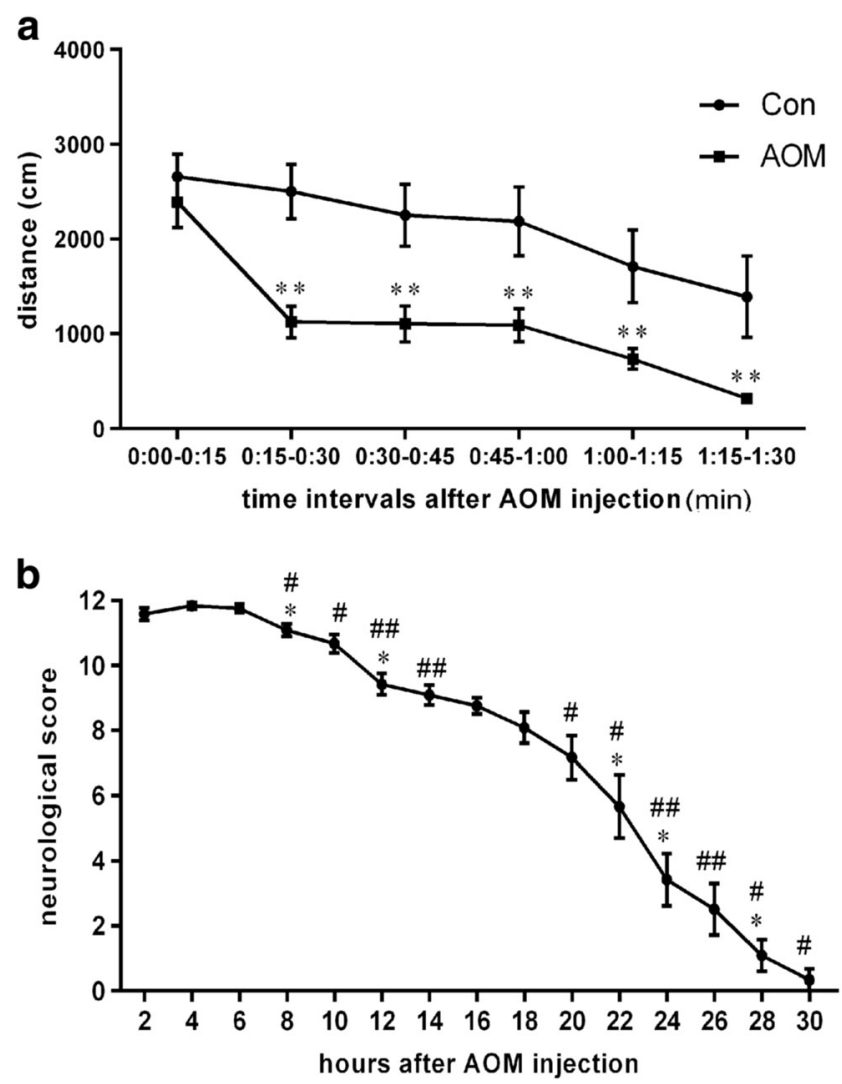

Fig. 1 Novel-cage activity and neurological assessment. a Shorter distance traveled by AOM-injected mice shortly after placing into a new cage; ${ }^{*} p<0.01, n=9$. b Decreased neurological score following AOM injection. Asterisk indicates $p<0.05$ vs. the results of the previous session $(2 \mathrm{~h}$ earlier), and hashtag indicates $p<0.05(p<0.01)$ vs. 4-hearlier session; $n=12$. Results are means \pm SEM

cortex of the abovementioned representative presynaptic and postsynaptic proteins.

\section{Material and Methods}

\section{AOM Model of Acute Liver Failure in Mice}

All experiments were performed with agreement of local animal ethical committee in Warsaw in accordance with EC Directive 86/609/EEC. Male C57BL/6 mice (animal colony of the Mossakowski Medical Research Centre, Polish Academy of Sciences in Warsaw), body weight $30.0 \pm 5.1 \mathrm{~g}$, were subjected to a hepatotoxic insult by single, intraperitoneal AOM injection at $100 \mathrm{mg} / \mathrm{kg}$ b.w. The mice had free access to water and chow and were housed in constant temperature, humidity, and 12-h light-dark cycling. If not otherwise stated, experiments were performed in the asymptomatic stage, $4 \mathrm{~h}$ after AOM injection, and symptomatic stage, $18 \mathrm{~h}$ after AOM injection. The selection of the time points was based on the neurological performance of mice. 

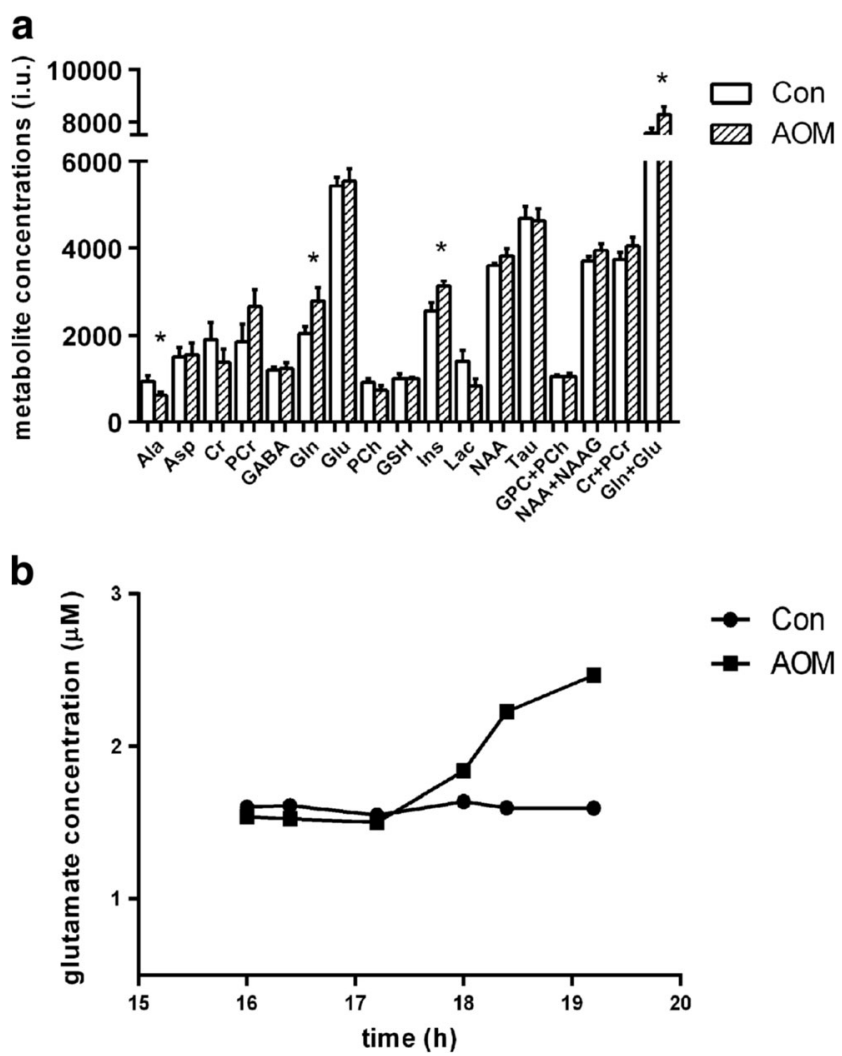

Fig. 2 Metabolite analysis by ${ }^{1} \mathrm{H}$ magnetic resonance spectroscopy technique and cerebral cortex microdialysis of AOM mice. a Spectrometric analysis revealed ALF-specific changes in cerebral cortex of AOM mice. Asterisk indicates $p<0.05$ vs. Con; $n=12$. Analyzed metabolites Ala alanine, Asp aspartic acid, $\mathrm{Cr}$ creatine, $\mathrm{PCr}$ phosphocreatine, GABA gamma-aminobutyric acid, Gln glutamine, Glu glutamate, $P C h$ phosphocholine, GSH glutathione, INS myo-inositol, Lac lactate, NAA N-acetylaspartate, Tau taurine, GPC glycerophosphocholine, $N A A G \mathrm{~N}$-acetylaspartylglutamate. b Extracellular glutamate concentration, as determined in microdialysates from freely moving mice, was significantly elevated after AOM administration; $n=4$. Results are means \pm SEM

\section{Activity Assessment}

For activity assessment, immediately after AOM $(n=11)$ or saline $(n=5)$ injections, the mice were placed individually in novel cages $(43 \times 27 \times 15 \mathrm{~cm})$, with fresh bedding, covered by a metal $1 \times 1-\mathrm{cm}$ grid to allow observation from above. The experiment room was illuminated by dim red light. The animals were recorded by an infrared acA1300-60NIR camera (Bassler AG, Germany) for $4 \mathrm{~h}$, and the activity was measured using Ethovision XT 10 (Noldus Information Technology, Netherlands).

\section{Neurological Assessment}

Neurological decline was determined in a group of mice $(n=12)$ by measuring the corneal reflex, pinna reflex, vibrissae reflex, startle reflex, righting reflex, and postural reflex $[16,19]$, with each given a score of 0 (no reflex evident), 1 (weak or delayed reflex), or 2 (regular reflex), resulting in a neurological score in the range of 0 to 12 . The reflexes were measured every $2 \mathrm{~h}$ after AOM injection. Corneal reflex was assessed by touching the eye with saline-soaked cotton applicator and observing a blink response $[14,20]$. To determine pinna reflex, the earlobe was touched with a cotton rod and ear retraction was observed $[20,21]$. To assess vibrissae response, the whiskers were brushed and reactional head movement was observed [21, 22]. Startle reflex was tested by presenting a sudden, unexpected noise and evaluating the reaction of the animal $[15,23]$. Righting reflex was determined by placing the mice on their backs and assessing how fast they right themselves [20, 24]. Postural reflex was tested by placing the mice individually in a cage without bedding and rapidly moving it in cardinal directions and judging how the animals try to keep their balance $[20,25]$.

\section{Biochemical Blood Analyses}

\section{Enzymatic Determination of Liver Enzymes and Ammonia in Serum}

Blood was collected into Eppendorf and after the formation of a clot, centrifuged at $8000 \times g$ for $6 \mathrm{~min}$. Then using enzymatic tests for ammonia, alanine aminotransferase (ALT) and aspartate aminotransferase (AST), the absorbance were measured at a wavelength of $340 \mathrm{~nm}$ after mixing probe with reagent and every $60 \mathrm{~s}$ for $2 \mathrm{~min}$ in $37^{\circ} \mathrm{C}$. Using an appropriate model, based on the difference in absorbance in time ( $\Delta \mathrm{abs} / \mathrm{min}$ ), results are expressed as IU/1.

\section{Cytokine IL-6 and TNF- $\alpha$ Concentrations in Serum}

Blood was collected into Eppendorf and after the formation of a clot, centrifuged at $6500 \times \mathrm{g}$ for $10 \mathrm{~min}$. The microspherebased immunoassay (cytometric bead array (CBA); BD Biosciences) was performed in accordance to the commercial protocol with modifications [26]. Briefly, six microsphere populations with distinct fluorescence intensities were dyed with proprietary dyes (emission $650 \mathrm{~nm}$ ). These beads were coated with capture antibodies against cytokines and mixed with recombinant standards or serum and the phycoerythrin (PE)-conjugated cytokine antibodies (emission $585 \mathrm{~nm}$ ) to form sandwich complexes. The instrument setup was performed with CaliBRITE beads, and the cytometer setup beads (BD) were done according to the manufacturer's instructions; 2000 events were measured and analyzed. A monomeric microsphere population was gated on forward and side scatters. Data were analyzed in two-color fluorescence dot plots representing the different microsphere populations (emission $650 \mathrm{~nm}$ ) and the cytokine concentration (according to PE emission $585 \mathrm{~nm}$ ). Mean fluorescence intensity values were 
collected. Four-parametric logistic calibration curves were used, and results were expressed as $\mathrm{pg} / \mathrm{ml}$.

\section{Metabolite Analysis by ${ }^{1} \mathrm{H}$ Magnetic Resonance Spectroscopy Technique and Cerebral Cortex Microdialysis of Symptomatic AOM Mice}

\section{${ }^{1}$ H Magnetic Resonance Spectroscopy Acquisition and Processing}

To obtain the spectra of brain metabolites, localized proton spectroscopy (Biospec 70/30USR) at short echo was performed using PRESS sequence $(\mathrm{TR} / \mathrm{TE}=2000 / 20 \mathrm{~ms}, 512$ averages, 2048 points, scan time $=17 \mathrm{~min}$ ) with VAPOR water suppression, the outer volume suppression, and frequency drift correction (flip angle $5^{\circ}$ ). Eddy current correction was performed at the scanner. Each measurement was carried out in two separated volumes of interest (VOI). The VOI $\left(4 \times 2 \times 1.5 \mathrm{~mm}^{3}\right)$ encompassed the frontal cortex. Linear and second-order global shims were adjusted with ADJ_1st_2nd_order protocol. Afterwards, linear and second-order local shims were automatically adjusted with FASTMAP in a cubic volume which contained the volume of interest region $\left(4 \times 4 \times 4 \mathrm{~mm}^{3}\right.$ for the frontal cortex). The unsuppressed water line width was typically maintained at around 9-12 Hz.

Metabolite concentrations were determined using a linear combination analysis method LCModel [27] (http://www.sprovencher.com/pages/lcmodel.shtml). The unsuppressed water signal measured from the same volume of interest was used as internal reference for absolute metabolite quantification. Metabolite concentrations are reported in institutional unit (IU). The spectrum signal to noise ratio was typically at around $12-25$.

\section{Microdialysis on Freely Moving Mice}

Mice were anesthetized with isoflurane (3.5\% in air), placed in a stereotaxic frame, and kept asleep at a flow rate of $1.5 \%$. The head was shaved and decontaminated by $70 \%$ ethanol, and two 1.2-mm-diameter holes were drilled, first at coordinates AP $-0.5, \mathrm{ML}+0.5$, in which skull screw was inserted, and second at coordinates $\mathrm{AP}+2.0, \mathrm{ML}-0.5, \mathrm{DV}-0.5$ according to the atlas [28], in which a guide cannula was inserted. Guide cannula was implanted at a depth of $0.5 \mathrm{~mm}$. Skull surface and guide cannula were secured with dental acrylic cement. Before arousals, antibiotic (Baytril, 2.5\%; $0.2 \mathrm{ml} / \mathrm{kg} \mathrm{b.w.)}$ and a painkiller (Ketonal, $2.5 \mathrm{mg} / \mathrm{kg}$ b.w.) were subcutaneously administered. Animals were placed in 21-cm-diameter cylindrical cages with ad libitum access to food and water. One day after surgery, mice were anesthetized with isoflurane (3.5\% in air) and a probe was implanted. After preparing the probe in accordance with the instructions, ACSF of the following composition (in $\mathrm{mM}$ ): $\mathrm{NaCl}$ (130), $\mathrm{KCl}$ (5), $\mathrm{CaCl}_{2}$ (2.5), $\mathrm{MgSO} 4$ (1.3), $\mathrm{KH}_{2} \mathrm{PO}_{4}$ (1.25), $\mathrm{NaHCO}_{3}$ (26), and Dglucose (10), bubbled with a mixture of $95 \% \mathrm{O}_{2}$ and $5 \% \mathrm{CO}_{2}$ passes through it. After $1 \mathrm{~h}$ in $2.5-\mu \mathrm{l} / \mathrm{h}$ flow, samples were collected every $40 \mathrm{~min}(100 \mu \mathrm{l})$ for $4 \mathrm{~h}$ (six fractions). After this, AOM was i.p. injected, and after $16 \mathrm{~h}$, samples were collected every $40 \mathrm{~min}$. All samples were immediately frozen at $-80{ }^{\circ} \mathrm{C}$.

\section{High-Performance Liquid Chromatography Determination of Glutamate}

Glutamate concentration in mice microdialysates was measured using HPLC with fluorescence detection after derivatization in a timed reaction with o-phthalaldehyde plus mercaptoethanol, exactly as described earlier [29].

\section{Electrophysiological Studies}

The brains were rapidly removed from the skulls and immersed in an ice-cold ACSF of the following composition (in $\mathrm{mM}$ ): $\mathrm{NaCl}$ (130), $\mathrm{KCl}$ (5), $\mathrm{CaCl}_{2}$ (2.5), $\mathrm{MgSO}_{4}$ (1.3), $\mathrm{KH}_{2} \mathrm{PO}_{4}$ (1.25), $\mathrm{NaHCO}_{3}$ (26), and D-glucose (10), bubbled with a mixture of $95 \% \mathrm{O}_{2}$ and $5 \% \mathrm{CO}_{2}$. Frontal cortical slices, $400 \mu \mathrm{m}$ thick, were cut in the coronal plane using a vibrating microtome (Leica). Slices were stored at $32.0 \pm 0.5{ }^{\circ} \mathrm{C}$.

\section{FP Recording and LTP Induction}

Individual slices were placed in the recording chamber of an interface type which was superfused $(2.5 \mathrm{ml} / \mathrm{min})$ with a modified ACSF (temperature $32.0 \pm 0.5^{\circ} \mathrm{C}$ ) containing (in mM) $\mathrm{NaCl}$ (132), $\mathrm{KCl}$ (2), $\mathrm{CaCl}_{2}$ (2.5), $\mathrm{MgSO}_{4}$ (1.3), $\mathrm{KH}_{2} \mathrm{PO}_{4}$ (1.25), $\mathrm{NaHCO}_{3}$ (26), and D-glucose (10), bubbled with $95 \% \mathrm{O}_{2}$ and $5 \% \mathrm{CO}_{2}$ (temperature $32.0 \pm 0.5^{\circ} \mathrm{C}$ ). A concentric bipolar stimulating electrode (FHC, USA) was placed in cortical layer V. Stimuli of $0.033-\mathrm{Hz}$ frequency and duration of $0.2 \mathrm{~ms}$ were applied using a constant-current stimulus isolation unit (WPI). Glass micropipettes filled with ACSF (2$5 \mathrm{M} \Omega$ ) were used to record field potentials. Recording microelectrodes were placed in cortical layer II/III. The responses were amplified (EXT 10-2 F amplifier, NPI), filtered (1 Hz$1 \mathrm{kHz}), \mathrm{A} / \mathrm{D}$ converted (10-kHz sampling rate), and stored on PC using the Micro1401 interface and Signal 2 software (CED). A stimulus-response (input-output) curve was made for each slice. To obtain the curve, stimulation intensity was gradually increased stepwise ( 15 steps; $5-100 \mu \mathrm{A})$. One response was recorded at each stimulation intensity. Then, stimulation intensity was adjusted to evoke responses of $30 \%$ of the maximum amplitude. LTP was induced by theta burst stimulation (TBS). TBS consisted of 10 trains of stimuli at $5 \mathrm{~Hz}$, repeated 5 times every $15 \mathrm{~s}$. Each train was composed 
of five pulses at $100 \mathrm{~Hz}$. During TBS, pulse duration was increased to $0.3 \mathrm{~ms}$.

\section{Whole-Cell Recording}

Individual slices were placed in the recording chamber mounted on the stage of the Axioskop (Zeiss) microscope and superfused at $2 \mathrm{ml} / \mathrm{min}$ with ACSF. Recording pipettes were pulled from borosilicate glass capillaries (Harvard Apparatus) using Sutter Instrument P97 puller. The pipette solution contained (in $\mathrm{mM}$ ) $130 \mathrm{~K}$-gluconate, $5 \mathrm{NaCl}, 0.3$ $\mathrm{CaCl}_{2}, 2 \mathrm{MgCl}_{2}, 10$ HEPES, $5 \mathrm{Na2}$-ATP, $0.4 \mathrm{Na}$-GTP, and 1 EGTA (osmolality $290 \mathrm{mOsm}, \mathrm{pH}=7.2$ ). Pipettes had open tip resistance of approximately $6 \mathrm{M} \Omega$. Pyramidal cells were sampled from the sites located approximately $2 \mathrm{~mm}$ lateral to the midline and approximately $0.3 \mathrm{~mm}$ below the pial surface. Signals were recorded using the SEC 05LX amplifier (NPI), filtered at $2 \mathrm{kHz}$, and digitized at $20 \mathrm{kHz}$ using Digidata 1440A interface and Clampex 10 software (Molecular Devices).

After obtaining the whole-cell configuration and subsequent 10-min stabilization period, the firing characteristics of the recorded cells were assessed using intracellular injections of rectangular current pulses of increasing amplitude (duration $400 \mathrm{~ms}$ ) in the current clamp mode. For each cell, the relationship between injected current intensity and the number of spikes was plotted. The gain was determined as a slope of the straight line fitted to experimental data. The threshold current $\left(I_{\text {th }}\right)$ was determined as a current extrapolated at zero firing rate. To record sEPSCs, neurons were voltage clamped at $-76 \mathrm{mV}$ and synaptic events were recorded for $4 \mathrm{~min}$ as inward currents. To record mEPSCs in some experiments, $1 \mu \mathrm{M}$ tetrodotoxin (TTX) was added to the ACSF spontaneous and miniature EPSCs were detected offline using the automatic detection protocol (Mini Analysis software, Synaptosoft Inc.) and subsequently checked manually for accuracy. Data were accepted for the analysis when the access resistance ranged between 15 and $18 \mathrm{M} \Omega$ and it was stable ( $<25 \%$ change) during recording. The threshold amplitude for the detection of an EPSC was set at $5 \mathrm{pA}$.

\section{Transmission Electron Microscopy}

The animals were anesthetized and perfused through the ascending aorta with $2 \%$ paraformaldehyde and $2.5 \%$ glutaraldehyde in $0.1 \mathrm{M}$ cacodylate buffer, $\mathrm{pH}$ 7.4. The cerebral cortex was fixed in the same solution for $20 \mathrm{~h}\left(\right.$ at $\left.4{ }^{\circ} \mathrm{C}\right)$ and placed in a mixture of $1 \% \mathrm{OsO}_{4}$ and $0.8 \% \mathrm{~K}_{4}\left[\mathrm{Fe}(\mathrm{CN})_{6}\right]$. Electron microscopy analysis was performed on 10 sections from each experimental and control animals. Synapses were classified according to their morphology. For the analysis, only asymmetric (i.e., excitatory) synapses were taken into account. Sv were quantified by counting them in all visible synapses at each section (in all fields). Sv were counted in specimens from control and symptomatic AOM animals. The average number of the vesicles was calculated for each group.

\section{Immunoblotting Analyses}

Immediately removed mice brain cortex was isolated on ice, homogenized in buffer $(20 \mathrm{mM}$ Tris-HCl, $\mathrm{pH} 6.8 ; 137 \mathrm{mM}$ $\mathrm{NaCl} ; 2$ mM EDTA; $1 \%$ Triton X-100; 0.5 mM DTT; $0.5 \mathrm{mM}$ PMSF; Phosphatase Inhibitor cocktail 1:100; Protease Inhibitor Cocktail 1:200), and centrifuged at $12000 \times g$ for 10 min. To separate P2 and S2 fractions, cortex was homogenized in buffer $(15 \mathrm{mM}$ Tris-HCl, $\mathrm{pH} 7.6 ; 0.25 \mathrm{M}$ sucrose, $1 \mathrm{mM}$ DTT; 0.5 mM PMSF, Phosphatase Inhibitor Cocktail 1:100; Protease Inhibitor Cocktail 1:200) and centrifuged at $1000 \times g$ for $10 \min \left(4^{\circ} \mathrm{C}\right)-\mathrm{P} 1$ fraction. Separated supernatant was centrifuged at $14000 \times g$ for $20 \mathrm{~min}\left(4^{\circ} \mathrm{C}\right)$ and $\mathrm{S} 2$ fraction (supernatant) was collected. The pellet, after buffer addition, was frozen as P2 fraction. Protein concentrations for both assays were performed using a BCA Protein Assay from Thermo Scientific (Pierce, Rockford, IL, USA).

The content of synaptic proteins was assessed by immunoblotting as previously described [30, 31]. Cortex homogenates/S2 fraction/P2 fraction were loaded with 15$30 \mu \mathrm{g}$ of protein diluted in Laemli buffer per each tissue sample and loaded in $10 \%$ SDS-PAGE gels, then transferred on to PVDF membrane. The purity of S2 and P2 fractions was further analyzed by immunoblotting using antibodies against lactate dehydrogenase (LDH) and cadherin as cytosolic and membrane fraction markers, respectively. Western blot membranes were blocked in 5\% milk and incubated overnight at $4{ }^{\circ} \mathrm{C}$ with antibodies (against nNOS, NR1, PSD-95, synaptophysin, synaptotagmin, syntaxin-1, Munc 18-1, vti1a) in recommended dilution in $1 \%$ milk and then for $1 \mathrm{~h}$ in $1 \%$ milk with secondary reagents. The protein bands were visualized with enhanced chemiluminescence, using G-BOX (Syngene). Data were expressed as fold change in fluorescent band intensity of target antibody divided by GAPDH, which is used as a loading control. The values of vehicle or control groups were used as a baseline and set to a relative protein expression value of 1 . All band intensity quantifications were analyzed using GeneTools.

\section{Statistical Analyses}

An ANOVA followed by Dunnett post hoc test was used to detect intervals in which significant changes occurred for all data sets where a parameter was measured across time points within a treatment. Student's $t$ test or the Mann-Whitney $U$ test was applied when two populations of responses were examined. Error bars represent the SD or SEM, which is specifically indicated, $* p<0.05, * * p<0.01$, and $* * * p<0.001$. 


\section{Results}

\section{Characteristics of the AOM Model}

Activity assessment revealed a difference between control and AOM-injected animals in the distance traveled following placing in a novel cage (Fig. 1a). Repeated measures ANOVA showed a strong effect of treatment $[F(1,14)=15.66$, $p<0.01]$ and testing time $[F(5,70)=23.51, p<0.001]$ as well as treatment $\times$ time effect $[F(5,70)=2.47, p<0.05]$. The activity of both groups gradually decreased; however, AOM mice started traveling shorter distances as early as $15-30 \mathrm{~min}$ postinjection, as demonstrated by planned comparisons $(p<0.01$ for all time intervals after $0-15 \mathrm{~min}$ ).

The neurological score at each time point was defined as the summation of six reflexes, and the average values can be seen in Fig. 1b. Continuous and significant neurological decline towards coma was observed starting from the sixth hour following AOM injection, as revealed by Friedman nonparametric analysis $(p<0.001)$ followed by individual Wilcoxon comparisons of dependent groups.

$\mathrm{AOM}$ injection led to a significant increase in the concentration of ammonia and inflammatory cytokines, TNF- $\alpha$ and IL-6, and activities of liver damage marker enzymes, ALT and AST in plasma (Table 1). In vivo ${ }^{1} \mathrm{H}$ spectrometric analysis revealed ALF-specific changes including increase of Glu/Gln ratio and myo-inositol in cerebral cortex of AOM-treated mice (Fig. 2a). Extracellular Glu concentration, as determined in microdialysates from freely moving mice, started to increase on $17 \mathrm{~h}$ after AOM administration (Fig. 2b).

\section{Stage Dependence of Electrophysiological Responses of Cortical Slices from AOM Mice}

\section{FPs, PPF, and LTP}

Analyses of FPs revealed no significant differences in the stimulus-response relationship between slices prepared $4 \mathrm{~h}$ after AOM administration (AOM $4 \mathrm{~h}$ ) and control preparations (Fig. 3a). In contrast, in brain slices prepared from mice with neurological decline (AOM $18 \mathrm{~h}$ ), the amplitude of FPs was markedly lowered over a wide range of stimulation intensities (Fig. 4b). Parameters characterizing input-output curves of FPs, calculated using the Boltzmann fits, are summarized in Table 2. The mean amplitude of FPs, measured 60-75 min after delivery of TBS, to induce LTP, was $128.6 \pm 4.2 \%$ of baseline in the control asymptomatic group (Fig. 3b) and $141.1 \pm 6.1 \%$ of in the Con 18-h group (Fig. 4b). LTP was significantly attenuated in the slices obtained from AOMtreated animals both in asymptomatic stage $(108.5 \pm 6.2 \%$; $p<0.01$ vs. Con 4 h; Fig. 3b) and in symptomatic stage $(108.4 \pm 3.6 \% ; p<0.001$ vs. Con 18 h group; Fig. $4 b)$.
Despite a lack of changes in the amplitudes of FPs, in slices obtained from AOM mice at asymptomatic stage, PPF ratio was significantly increased (Con $4 \mathrm{~h} 117.6 \pm 5.1 \%$ vs. AOM 4 h $130.9 \pm 4.4 \%$; $p<0.05$; Fig. 3c1, c2). PPF was further increased in slices obtained $18 \mathrm{~h}$ after AOM administration (Con 18 h $121.5 \pm 3.5 \%$ vs. AOM 18 h $158.3 \pm 6.9 ; p<0.001$; Fig. 4c1, c2).

\section{Pyramidal Neuron Membrane Excitability}

Whole-cell recordings were obtained from layer II/III neurons exhibiting a regular spiking firing pattern in response to a depolarizing current pulse (Figs. $3 \mathrm{~d}$ and $4 \mathrm{~d}$ ). In slices prepared $4 \mathrm{~h}$ after AOM administration, the resting membrane potential of neurons was significantly different from control neurons $(-78.1 \pm 0.8$ vs. $-73.6 \pm 0.6 \mathrm{mV}$, respectively; $p<0.001)$. A similar difference existed between neurons in slices prepared $18 \mathrm{~h}$ after AOM injection and control cells $(-78.6 \pm 2.0 \mathrm{vs}$. $-73.4 \pm 0.7 \mathrm{mV}$, respectively; $p<0.05$ ). The input resistance of neurons originating from AOM $4 \mathrm{~h}$ mice was not different from that of the control group $(143.5 \pm 2.8 \mathrm{vs}$. $151.1 \pm 4.7 \mathrm{M} \Omega$, respectively; $p=0.36$ ); however, the input resistance of neurons originating from AOM 18-h mice was significantly lower from that of the respective control group $(123.4 \pm 11.6$ vs. $167.1 \pm 12.0 \mathrm{M} \Omega$, respectively; $p<0.01)$.

Analyses of the relationship between the injected current and the firing rate (gain; Figs. 3e and 4e) demonstrated that AOM did not modify the intrinsic excitability of pyramidal neurons. Neither in slices prepared 4 nor $18 \mathrm{~h}$ after AOM administration, the differences between experimental and control mice were significant (Figs. $3 \mathrm{f}$ and $4 \mathrm{f}$ ). However, in slices obtained $18 \mathrm{~h}$ after AOM administration, the calculated threshold current for the generation of the action potential was significantly higher than in the respective control mice (Con 18 h; $344.0 \pm 27.7$ vs. $236.6 \pm 17.2$ pA; $p<0.01$; Fig. 4g). This effect appears to be related to a markedly lower membrane resistance of neurons in the AOM 18-h group. In contrast, the average spike threshold current in the AOM 4-h mice was not different from the Con 4-h mice (Fig. 3g).

\section{Excitatory Postsynaptic Currents}

In the cells originating from the AOM 4-h mice, the mean frequency of sEPSCs was similar to respective control (Fig. 3j). Similarly, the mean amplitudes of sEPSCs in the AOM 4-h mice and in the respective control were not significantly different (Fig. 3k). However, in the cells originating from AOM 18-h mice, the mean frequency of sEPSCs was significantly lower in comparison to that in the cells from control animals $(1.0 \pm 0.1$ vs. $1.5 \pm 0.1 \mathrm{~Hz} ; p<0.001$; Fig. 4j). AOM, acting for $18 \mathrm{~h}$, also increased the mean amplitude of sEPSCs $(10.4 \pm 0.3$ vs. $9.5 \pm 0.2 \mathrm{pA} ; p<0.05$; Fig. $4 \mathrm{k}$ ), and additionally, it significantly increased the mean 


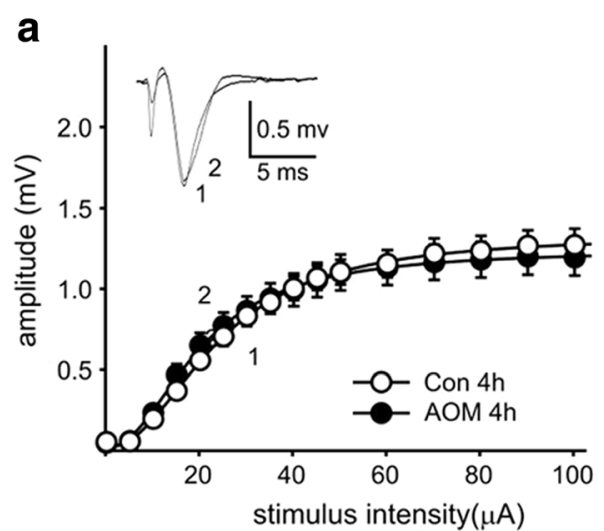

$\mathbf{C}_{1}$

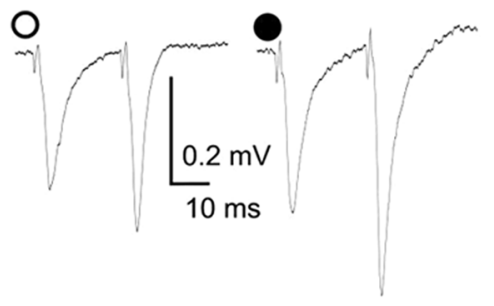

d Con $4 \mathrm{~h}$
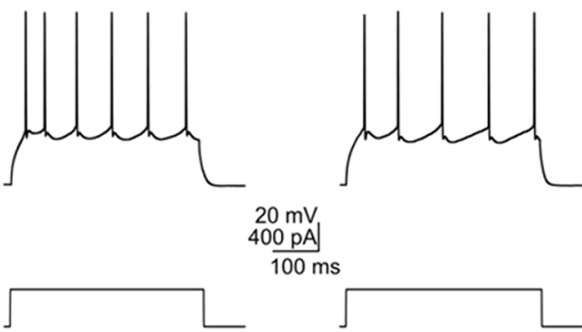

Fig. 3 Electrophysiology of ALF-induced changes in cerebrocortical slices obtained from AOM mice at asymptomatic stage. a-c2 The effects of AOM on FPs in slices prepared from asymptomatic mice (AOM $4 \mathrm{~h}$ ). a The amplitudes of FPs of control (Con $4 \mathrm{~h}$ ) and AOM mice (AOM 4 h). b Impairment of LTP. Insets in a, b show the superposition of averaged FPs recorded in representative experiments at times indicated by numbers. Arrows in b denote the TBS. c1 Examples of individual FPs evoked by paired stimuli in slices from control (open circles) and AOM-treated mice (filled circles). c2 Summary quantification of the average PPF ratio $( \pm$ SEM); $* p<0.05$. d-g In slices prepared from asymptomatic mice (AOM $4 \mathrm{~h}$ ), the basic electrophysiological properties of layer II/III pyramidal neurons remain unchanged (apart from the resting membrane potential, see text). d An example of response of control pyramidal neuron (left trace) and response of a cell from AOM-treated (AOM $4 \mathrm{~h}$ ) mouse (right trace) to a depolarizing current pulse (lower traces). e The injected current vs. spiking rate relationship in a cell originating from control mouse (open

decay time constant of sEPSCs (from $4.5 \pm 0.2$ to $5.9 \pm 0.3 \mathrm{~ms}$; $p<0.001$; Fig. $4 \mathrm{~m}$ ). AOM did not alter the mean rise time of sEPSCs either in the AOM 4-h mice (Fig. 31) or in the AOM 18-h mice (Fig. 4l).
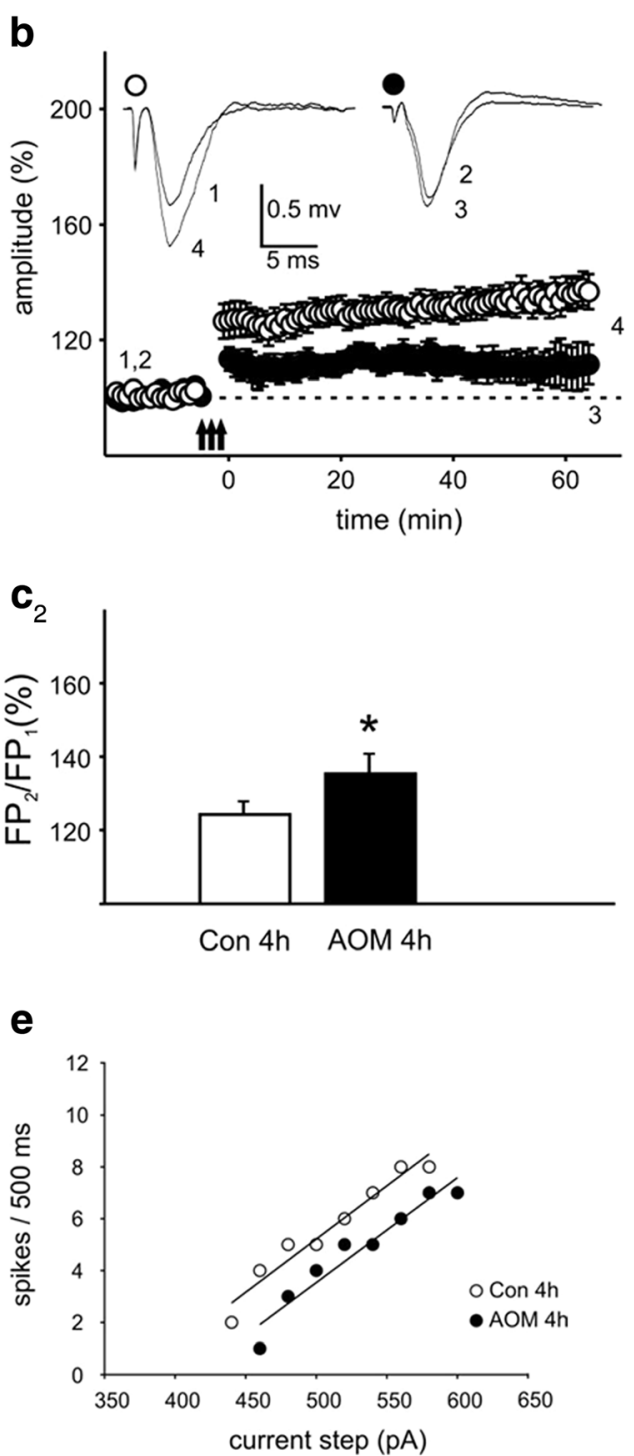

circles) and in a neuron originating from AOM-treated mouse (filled circles). Solid lines represent the linear fits to the experimental data. $\mathbf{f}$ The mean gain $( \pm$ SEM) and $\mathbf{g}$ mean firing threshold $( \pm$ SEM $)$ of pyramidal neurons prepared from control (white bars; 18 cells; $n=5$ ) and AOM-treated animals (black bars; 21 cells; $n=5$ ). $\mathbf{h}-\mathbf{m}$ Lack of changes in sEPSCs in slices from asymptomatic mice (AOM $4 \mathrm{~h}$ ). $\mathbf{h}$ Examples of raw records from control neuron (upper pair of traces) and neuron from AOM mouse (lower pair of traces) recorded before (Con $4 \mathrm{~h}$, AOM $4 \mathrm{~h}$ ) and after addition of TTX (Con $4 \mathrm{~h}+$ TTX, AOM $4 \mathrm{~h}+$ TTX). $\mathbf{i}$ The superposition of averages of all individual sEPSCs detected during 4 min baseline recordings from control neuron (thin line) and a neuron originating from an AOM-treated mouse (thick line). Bar graphs illustrate a lack of the influence of AOM on $\mathbf{j}$ mean frequency, $\mathbf{k}$ mean amplitude, $\mathbf{I}$ mean rise time, and $\mathbf{m}$ mean decay time constant of sEPSCs. In $\mathbf{j}-\mathbf{m}$, neurons originating from control mice, error bars represent the SEM (white bars; 18 cells; $n=5$ ) and AOM-treated animals (black bars; 21 cells; $n=5$ )

The effect of $\mathrm{Na}^{+}$channel blockade on recorded EPSCs was investigated in separate samples of neurons obtained from control and AOM-treated mice (Con $4 \mathrm{~h}$ vs. AOM $4 \mathrm{~h}$ and Con $18 \mathrm{~h}$ vs. AOM $18 \mathrm{~h}$ ). The addition of $1 \mu \mathrm{M}$ TTX to ACSF 
f

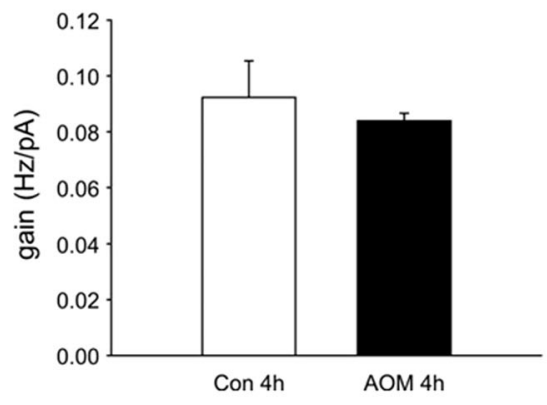

h

Con $4 \mathrm{~h}$

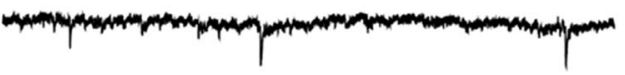

Con 4h + TTX

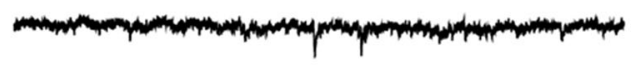

AOM 4h

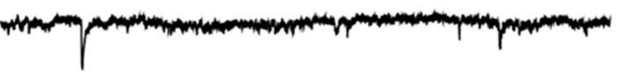

AOM $4 h+T T X$

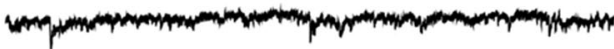

g

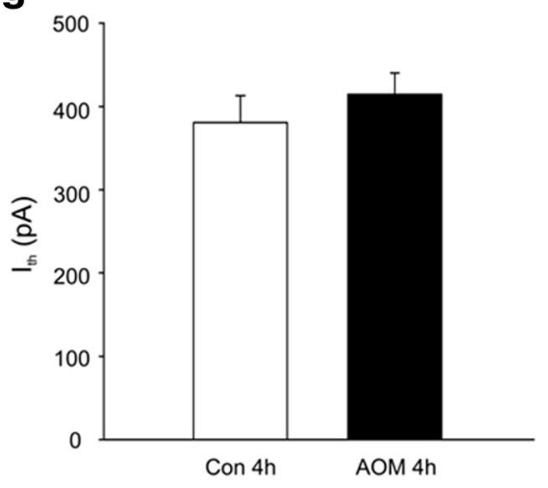

i
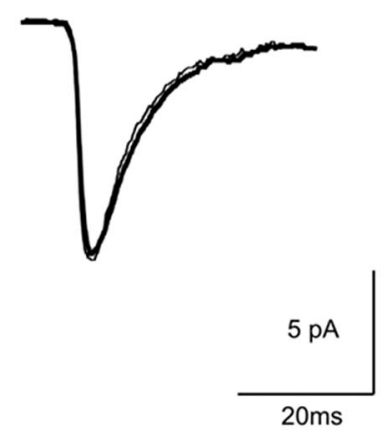

$\frac{10 \mathrm{pA}}{500 \mathrm{~ms}}$
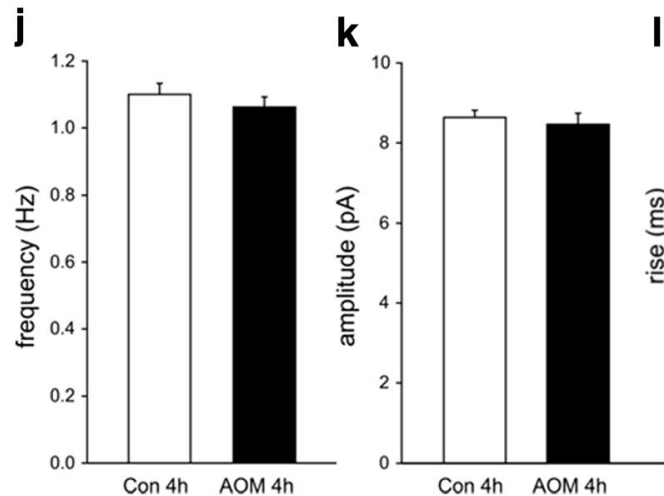

I
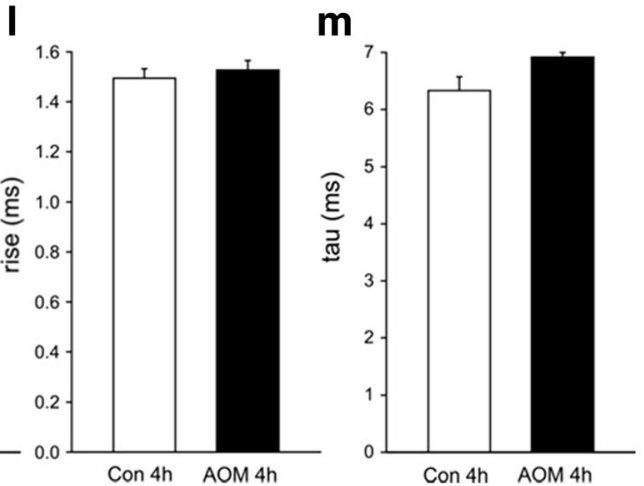

Fig. 3 (continued)

did not result in significant changes of the mean frequency, mean amplitude, mean rise, and mean decay time constant of sEPSCs (Table 3) either in control or in experimental groups. This finding indicates that in our whole-cell recordings, the contribution of action potential-induced release of neurotransmitter from presynaptic terminals is negligible.

\section{Ultrastructural Analysis of Cortical Synapses}

Electron microscopy analysis of the cortex from the symptomatic AOM mice showed an increased number of synapses showing abundance of sv in the presynaptic zone. The numbers of sv in randomly selected sections from symptomatic mice were $(\sim 15 \%)$ higher than in the control (Fig. 5a, b).

\section{Expression of Synaptic Proteins at Different Stages of ALF}

Presynaptic Proteins

The membrane to cytoplasm content ratio (P2/S2) of presynaptic proteins, synaptophysin and synaptotagmin, were 


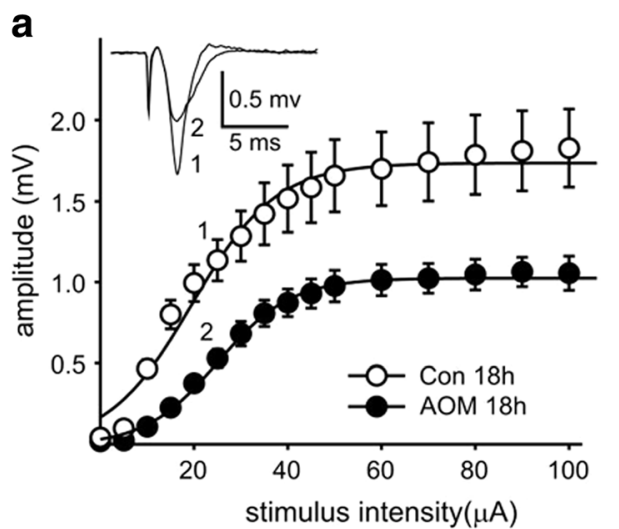

$\mathbf{c}_{1}$

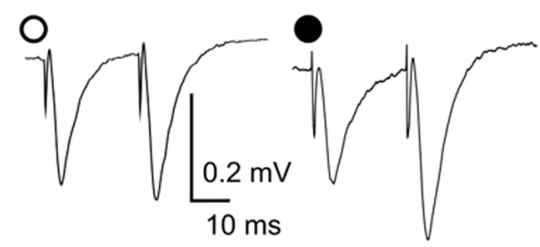

d $_{\text {Con } 18 \mathrm{~h}}$

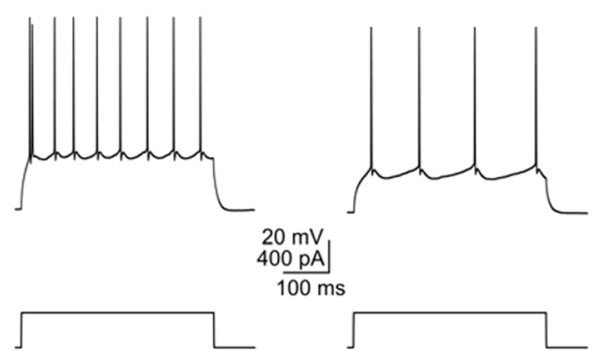

Fig. 4 Electrophysiology of ALF-induced changes in cerebrocortical slices obtained from AOM mice at symptomatic stage. a-c2 The effects of AOM on FPs in slices prepared from symptomatic mice (AOM $18 \mathrm{~h}$ ). a The amplitudes of FPs of control (Con $18 \mathrm{~h}$ ) and AOM mice (AOM $18 \mathrm{~h}$ ). b Impairment of LTP. c1 Examples of individual FPs evoked by paired stimuli in slices from control and AOM-treated mice. c2 Summary quantification of the average PPF ratio $( \pm \mathrm{SEM}) ; * * * p<0.001$. Symbols as in Fig. 3a-c2. d-g In slices prepared from symptomatic mice (AOM $18 \mathrm{~h}$ ), the excitability of layer II/III pyramidal neurons is reduced. d An example of response of control pyramidal neuron (Con $18 \mathrm{~h}$ ) (left trace) and response of a cell from symptomatic mouse (AOM $18 \mathrm{~h}$ ) (right trace) to a depolarizing current pulse (lower traces). e The injected current vs. spiking rate relationship in a cell from control mouse and in a neuron from AOM-treated mouse. $\mathbf{f}$ The mean gain $( \pm \mathrm{SEM})$ and $\mathbf{g}$ mean firing threshold $( \pm$ SEM) of pyramidal neurons prepared from control (23

decreased by $\sim 50$ and $\sim 30 \%$, respectively, in the frontal cortex of symptomatic mice as compared to the control and that of Munc $18-1$ was increased by $\sim 70 \%$ (Fig. $6 \mathrm{~b}$ ). The P2 fraction content of syntaxin-1 revealed an $\sim 20 \%$ increase, and the level of vtila protein, which characterizes vesicles driving spontaneous release, was significantly
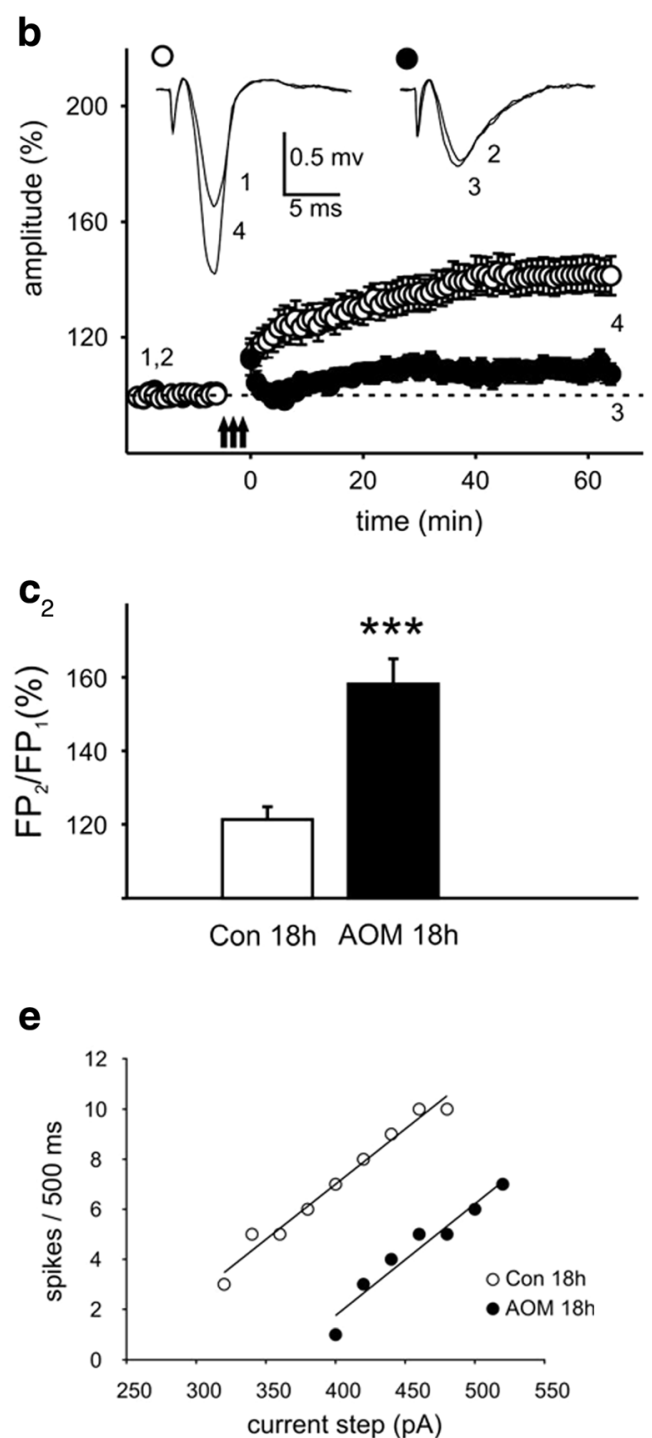

cells; $n=6$ ) and AOM-treated animals (21 cells; $n=6$ ); **p $<0.01$. Symbols as in Fig. $3 \mathbf{d}-\mathbf{g}$. $\mathbf{h}-\mathbf{m}$ sEPSCs in slices prepared from symptomatic rats (AOM $18 \mathrm{~h}$ ). $\mathbf{h}$ Examples of raw records from a control neuron (upper pair of traces) and a neuron from AOM mouse (lower pair of traces) recorded before (Con $18 \mathrm{~h}, \mathrm{AOM} 18 \mathrm{~h}$ ) and after addition of TTX (Con $18 \mathrm{~h}+$ TTX, AOM $18 \mathrm{~h}+$ TTX). i The superposition of averages of all individual sEPSCs detected during 4min baseline recordings from a control neuron (thin line) and a neuron originating from an AOM-treated mouse (thick line). Bar graphs illustrate the effect of AOM on $\mathbf{j}$ mean frequency, $\mathbf{k}$ mean amplitude, $\mathbf{I}$ mean rise time, and $\mathbf{m}$ mean decay time constant of sEPSCs. In $\mathbf{j}-\mathbf{m}$, neurons originating from control mice, error bars represent the SEM (white bars; 23 cells; $n=6$ ) and AOM-treated animals (black bars; 21 cells; $n=6) ; * p<0.05, * * p<0.01, * * * p<0.001$

decreased (Fig. 6c). In the AOM mice at the asymptomatic stage, neither the S2 nor the P2 content of synaptophysin was changed (Fig. 6d). The S2 protein content of synaptophysin increased gradually between asymptomatic and symptomatic stages (Fig. 6d). The cytosolic and membrane fraction markers LDH and cadherin were analyzed 
f

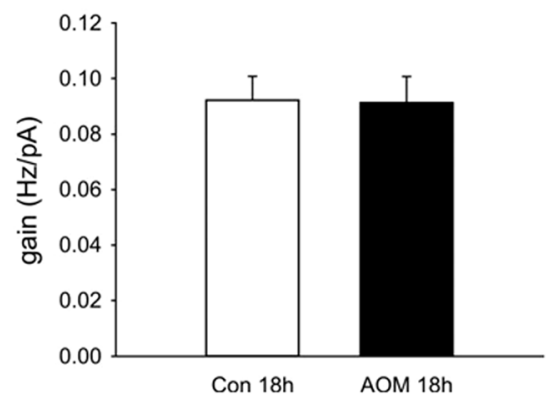

h

Con $18 \mathrm{~h}$

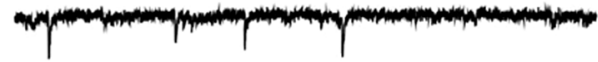

Con $18 \mathrm{~h}+\mathrm{TTX}$

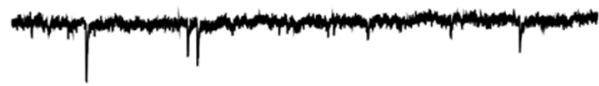

AOM $18 \mathrm{~h}$

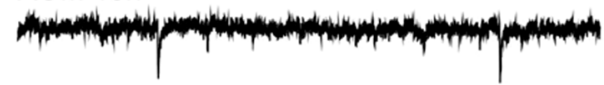

AOM $18 h+$ TTX

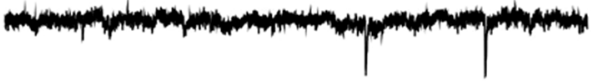

g

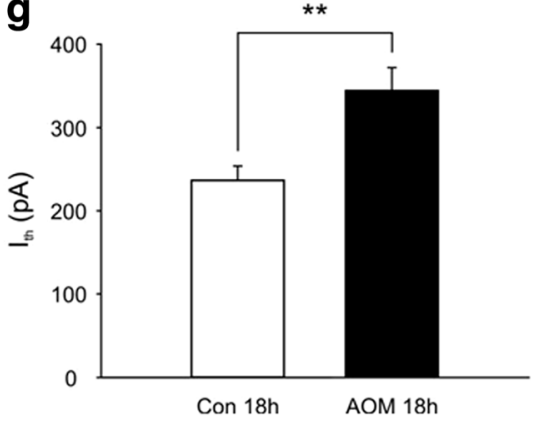

i

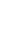
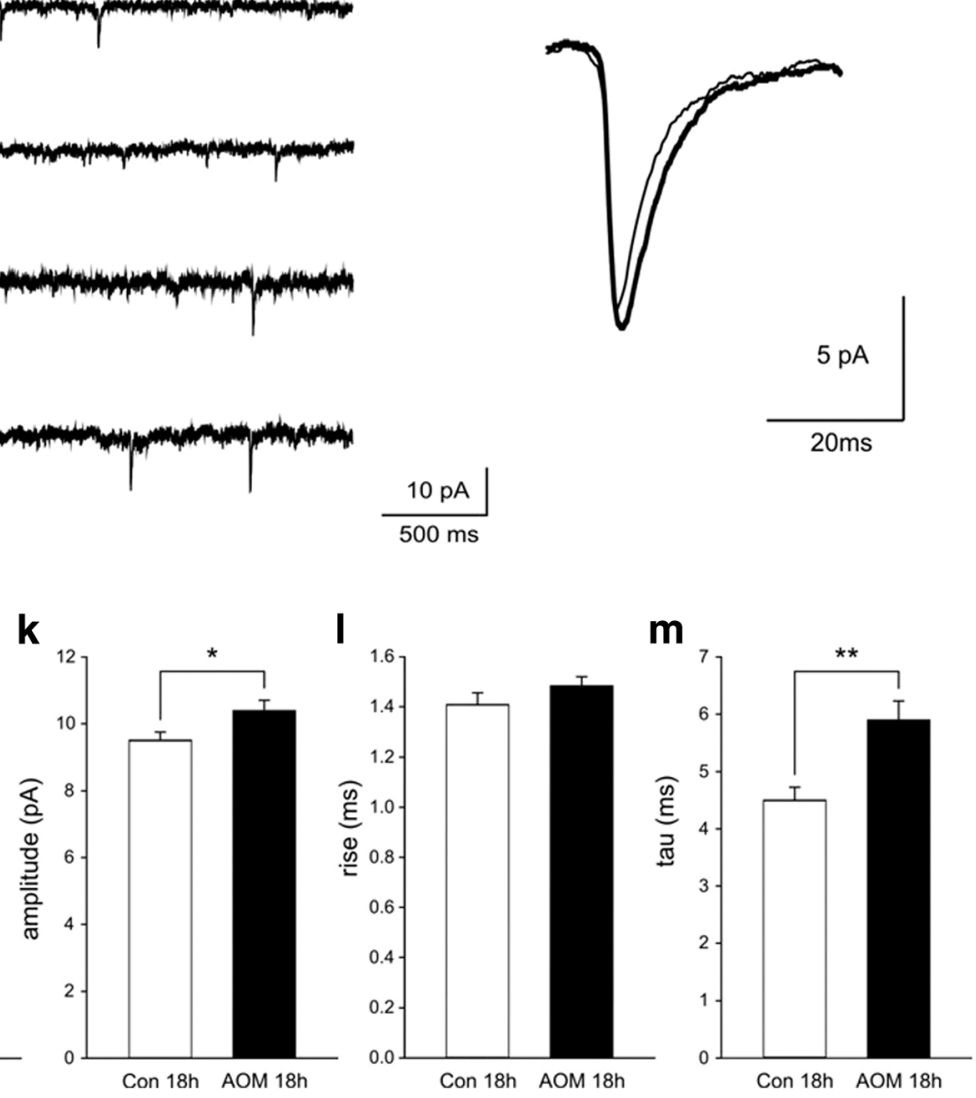

Fig. 4 (continued)

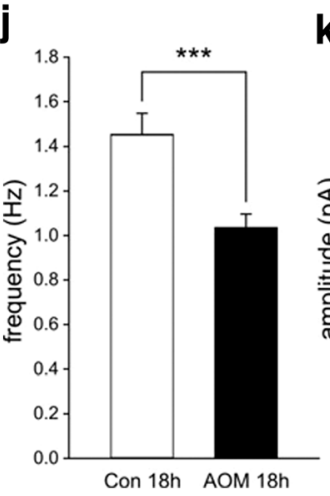

by immunoblotting and confirmed a purity of both fractions (Fig. 6a).

Table 2 Effects of the treatment with AOM on parameters characterizing stimulus-response curves of field potentials

\begin{tabular}{lllll}
\hline & $V_{\max }(\mathrm{Mv})$ & $U_{h}(\mu \mathrm{A})$ & $S$ & Number \\
\hline Con 4 h & $1.19 \pm 0.40$ & $23.86 \pm 3.20$ & $9.16 \pm 4.21$ & 11 \\
AOM 4 h & $1.13 \pm 0.39$ & $22.77 \pm 4.50$ & $8.14 \pm 4.10$ & 12 \\
Con 18 h & $1.80 \pm 0.40$ & $19.38 \pm 6.20$ & $8.20 \pm 3.59$ & 18 \\
AOM 18 h & $1.05 \pm 0.36^{*}$ & $27.77 \pm 5.04^{*}$ & $7.59 \pm 3.10$ & 25 \\
\hline
\end{tabular}

${ }^{*} p<0.001 ;$ AOM $18 \mathrm{~h}$ vs. control animals (Con $18 \mathrm{~h}$ )

\section{Postsynaptic Proteins}

Analysis of postsynaptic complex NMDAR/PSD-95/nNOS revealed $\sim 16, \sim 40$, and $\sim 35 \%$ increase of its particular components, i.e., NR1 subunit, PSD-95, and nNOS protein, respectively, in P2 fraction from the frontal cortex of symptomatic AOM-treated mice (Fig. 7a). Moreover, in the prodromal stage of AOM, the PSD-95, but not NR1 proteins level, was increased (Fig. 7b). 
Table 3 Comparison of sEPSC and mEPSC parameters in control and AOM-treated (4 and $18 \mathrm{~h}$ ) mice

\begin{tabular}{lllll}
\hline & Con $4 \mathrm{~h}$ & & Con 18 h & \\
& sEPSCs & mEPSCs & sEPSCs & mEPSCs \\
Frequency (Hz) & $1.1 \pm 0.1$ & $1.1 \pm 0.1$ & $1.3 \pm 0.1$ & $1.3 \pm 0.1$ \\
Amplitude (pA) & $8.4 \pm 0.2$ & $8.4 \pm 0.2$ & $9.4 \pm 0.2$ & $9.3 \pm 0.2$ \\
Rise (ms) & $1.5 \pm 0.1$ & $1.5 \pm 0.1$ & $1.4 \pm 0.0$ & $1.4 \pm 0.0$ \\
Tau (ms) & $6.2 \pm 0.3$ & $6.2 \pm 0.3$ & $4.6 \pm 0.1$ & $4.6 \pm 0.1$ \\
& AOM 4 h & & AOM 18 h & \\
& sEPSCs & mEPSCs & sEPSCs & mEPSCs \\
Frequency (Hz) & $1.1 \pm 0.1$ & $1.0 \pm 0.1$ & $1.0 \pm 0.0$ & $1.0 \pm 0.0$ \\
Amplitude (pA) & $8.9 \pm 0.4$ & $8.8 \pm 0.4$ & $10.3 \pm 0.2$ & $10.2 \pm 0.2$ \\
Rise (ms) & $1.5 \pm 0.1$ & $1.5 \pm 0.1$ & $1.5 \pm 0.1$ & $1.5 \pm 0.1$ \\
Tau (ms) & $6.8 \pm 0.2$ & $6.8 \pm 0.2$ & $5.9 \pm 0.1$ & $5.9 \pm 0.1$ \\
\hline
\end{tabular}

Data are presented as the mean \pm SEM

\section{a}
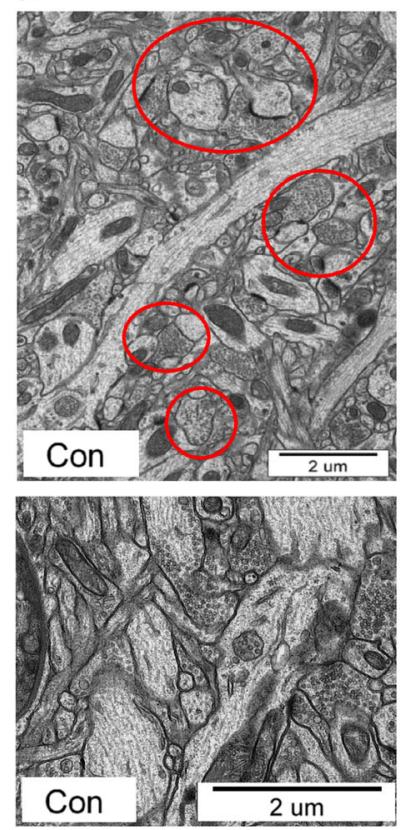
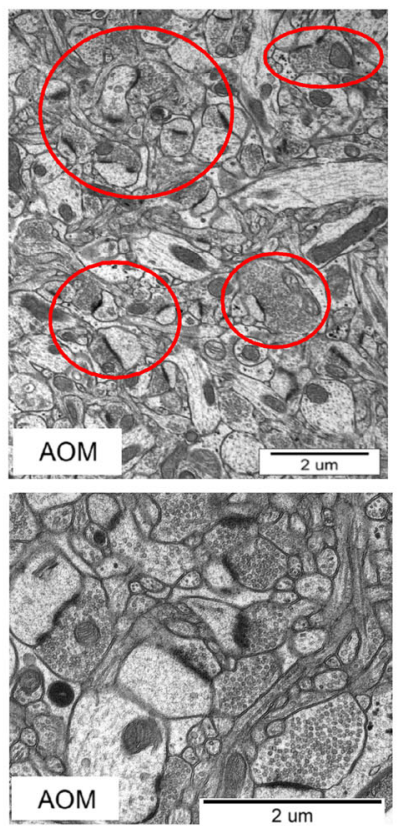

b

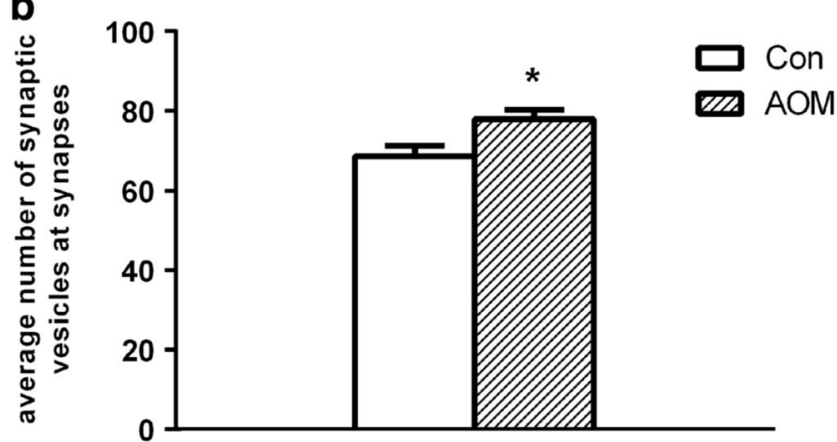

Fig. 5 Electron microscopy of the cerebral cortex of control and AOMtreated mice at symptomatic stage. a Representative synapses are indicated by red circles. b Average number of synaptic vesicles at synapses counted from 50 randomly selected synapses of control $(n=3)$ and AOM-treated mice $(n=4)$; asterisk indicates $p<0.05$ vs. control animals (Con). Results are means \pm SEM

\section{Discussion}

The present study provided an exhaustive description of alterations in synaptic transmission, ultrastructure, and expression of synaptic transmission-related proteins in the frontal cortex of mice with ALF. In our hands, the AOM model reproduced a wide spectrum of changes in blood and brain biochemistry as well as in neurophysiological and behavioral manifestations of ALF, each reflecting those reported for acute HE in different animal ALF models [25, 32-34] and the health status of patients with ALF [35-37]. Progression of neurological deficit in AOM-treated mice suggested that ALF could affect and/or modify information processing in mice frontal cortex and prompted us to carry out detailed investigations of electrophysiological properties of pyramidal neurons and excitatory synapses at the asymptomatic and symptomatic stage. The results documented that disturbances in neurotransmission coincide with impaired neurological status of the animals. At the asymptomatic stage, no significant changes in most parameters characterizing synaptic transmission, such as FP amplitude and the frequency and amplitude of sEPSCs/mEPSCs, were evident. However, despite lack of those changes, the PPF ratio was elevated at this stage. As in PPF, an increase in the amplitude of the response to the second pulse of a pair is determined by a presynaptic mechanism involving the residual calcium signal arising from calcium entry through voltagegated calcium channels [38]; this result may indicate that early effects of ALF, at asymptomatic stage, include disturbances in calcium-buffering mechanisms within presynaptic terminals. At the level of neurological status, the PPF ratio was higher than at the asymptomatic stage; however, this effect was accompanied by other marked changes including a reduction in the frequency of sEPSCs/mEPSCs.

As the number of glutamatergic synapses in the frontal cortex of AOM-treated mice appeared unchanged, the observed decrease in sEPSC/mEPSC frequency (Fig. 4j) was most likely due to a decreased probability of release of glutamate quanta from presynaptic terminals, which may also underlie a decrease in the amplitude of FPs. This conclusion is further supported by the finding that the distribution of synaptophysin, synaptotagmin, and vtila proteins was significantly distorted in the symptomatic AOM-injected mice.

At the level of neurological status, however, an increased amplitude and a longer decay time constant of sEPSCs/mEPSCs were also evident. These changes appear to be of postsynaptic origin, related to the reactivity and kinetics of ionotropic glutamate receptors and may be related to observed changes in the postsynaptic complex proteins. Moreover, in the symptomatic AOM-treated mice, a markedly lower membrane resistance of neurons was evident. These effects were not related to a direct action of ammonium ion on neurons [8] as the slices had been 
Fig. 6 Protein content of selected presynaptic proteins. a Purity of $\mathrm{S} 2$ and $\mathrm{P} 2$ fraction. b

Synaptophysin, synaptotagmin-1, and Munc 18-1 protein contents in the cerebral cortex of control and symptomatic AOM-treated mice shown as membrane (P2) to cytosolic (S2) fraction ratio (P2/ S2) $(n=8)$, followed by representative electrophorograms. c Syntaxin-1 and vtilA protein contents in membrane fraction (P2) in control and symptomatic AOM-injected mice $(n=8)$, followed by representative electrophorograms. d Changes in synaptophysin protein content in cytosolic (S2) and membrane fraction (P2) at prodromal and symptomatic stage of ALF $(n=6)$, followed by representative electrophorograms. Asterisk indicates $p<0.05$ vs. control animals (Con). Results are means \pm SEM
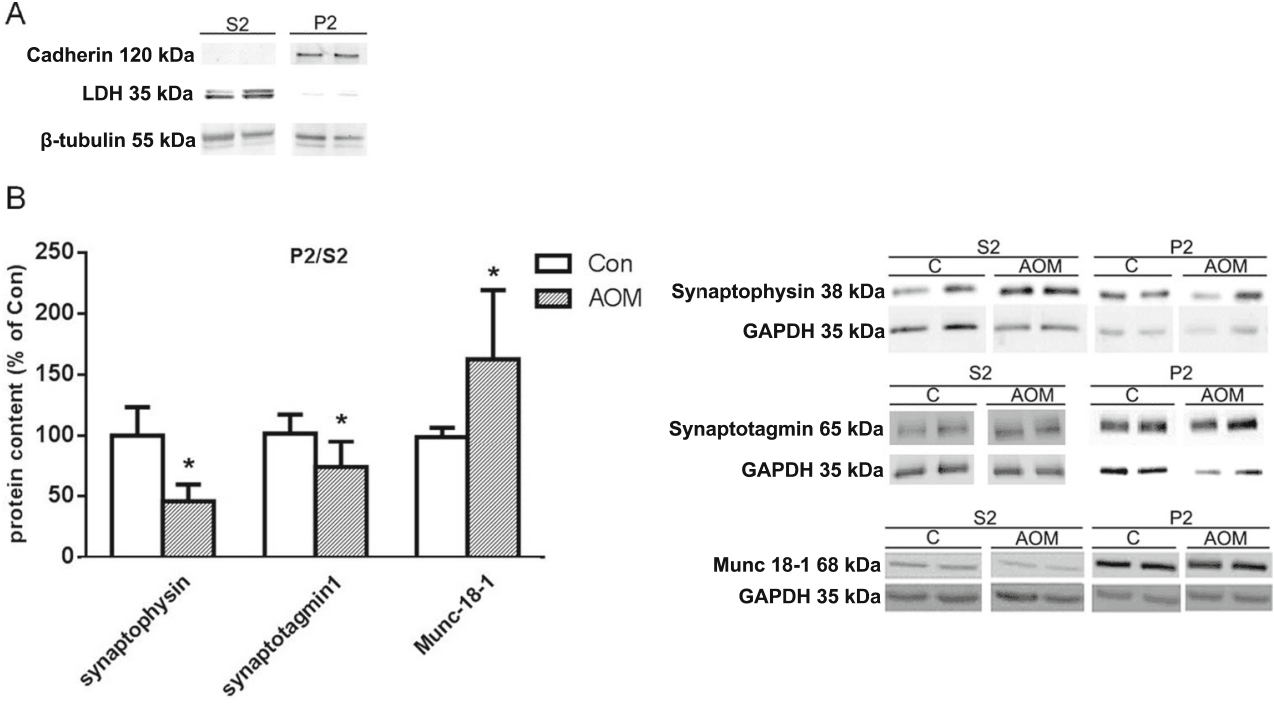

C
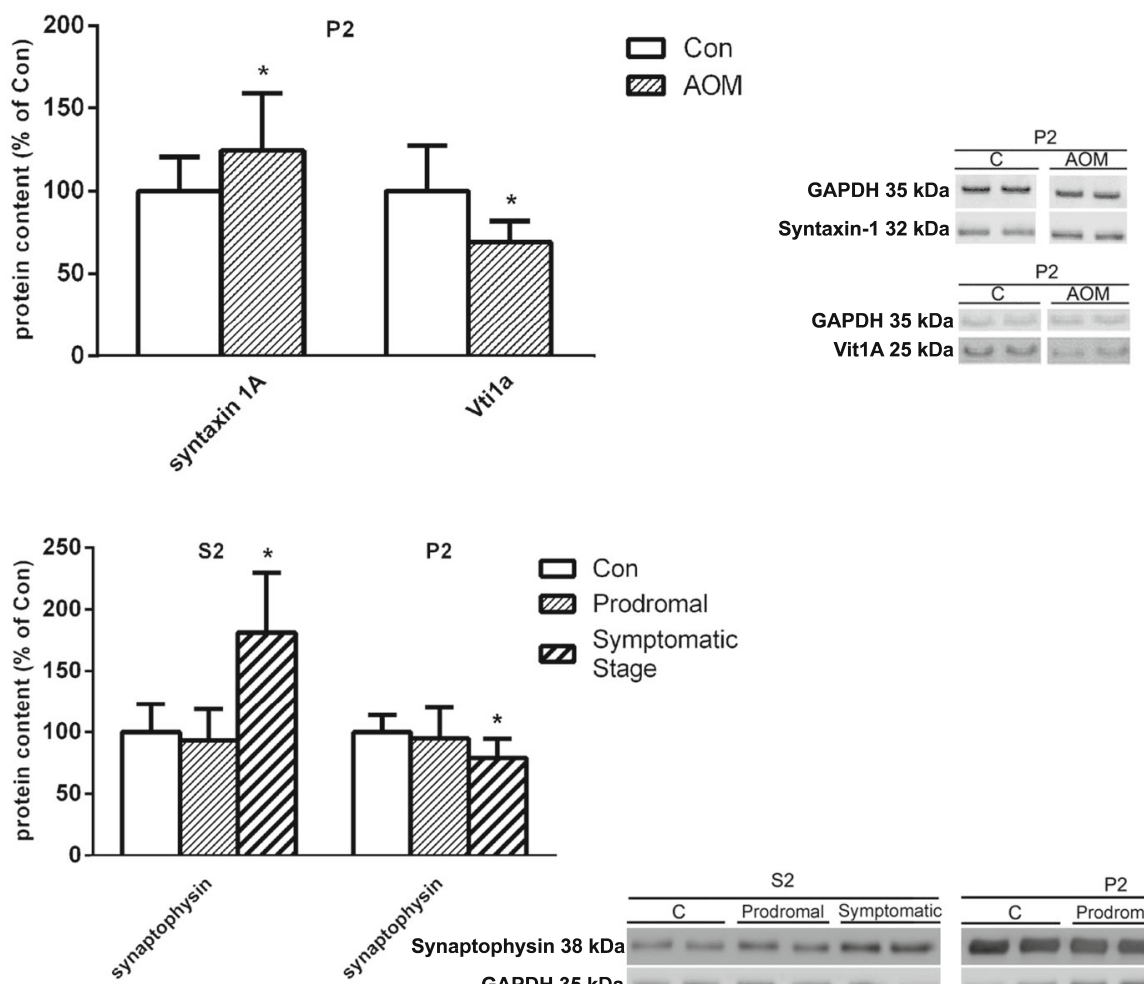

P2

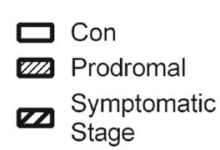

Vit1A $25 \mathrm{kDa}$ incubated for several hours in the ACSF before recordings began.

Quantification of sv and analysis of changes in the distribution of synaptic proteins further confirmed the contribution of presynaptic modifications to ALF-induced changes in neurotransmission in the model. The number of sv per synapse was found increased, which is consistent with the decrease of membraneto synaptoplasm content ratio of synaptophysin and synaptotagmin, suggesting a decreased efficiency of vesicle trafficking to the membrane. It is tempting to speculate that increased association with the membranes of the fusion protein Munc-18-1 and the docking protein syntaxin-1 may reflect their response of the deficient supply of vesicles for interaction with these proteins. However, analysis of the expression and positioning of many other components of the docking machinery, not considered here, including Munc-13, calcium-dependent activator protein for secretion, SNAP-25, and synaptobrevin-2 are needed to verify this speculation. The vps10p tail interactor 1a (vtila) protein, acting together with vesicle-associated membrane protein 7 , characterizes vesicles driving spontaneous release [11]. Since the postsynaptic currents measured corresponded to mEPSCs, a product of activity-independent, spontaneous release of glutamate from 
Fig. 7 Protein content of selected postsynaptic proteins. a PSD-95, nNOS, and NR1 protein contents in membrane fraction (P2) in control and symptomatic AOMtreated mice $(n=8)$, followed by representative electrophorograms. b Changes in PSD-95 and NR1 protein content in membrane fraction (P2) at prodromal and symptomatic stage of ALF $(n=6)$, followed by representative electrophorograms. Asterisk indicates $p<0.05$ vs. control animals (Con). Results are means \pm SEM
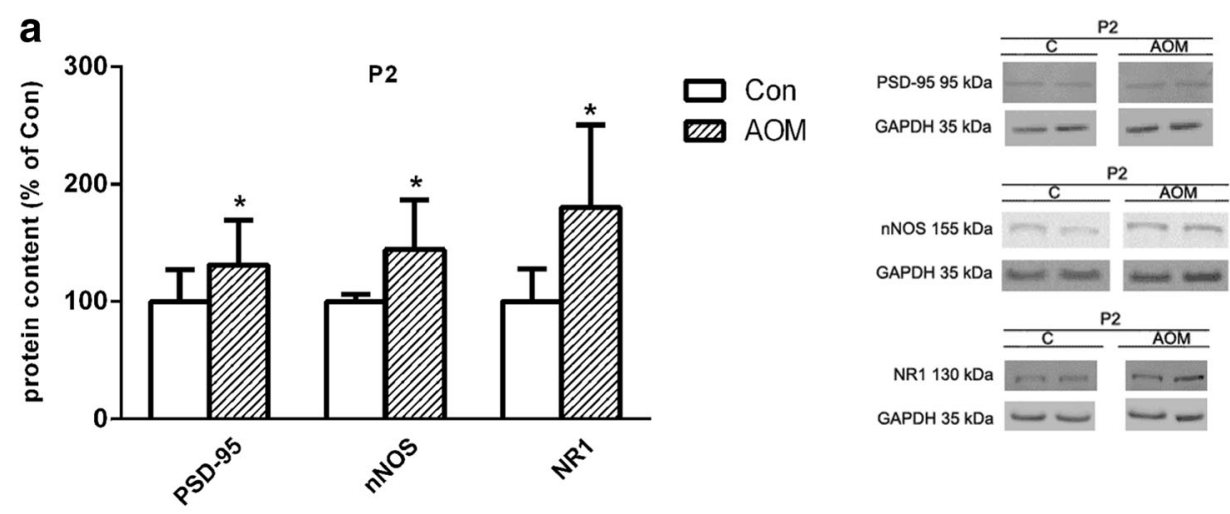

\footnotetext{
b
}

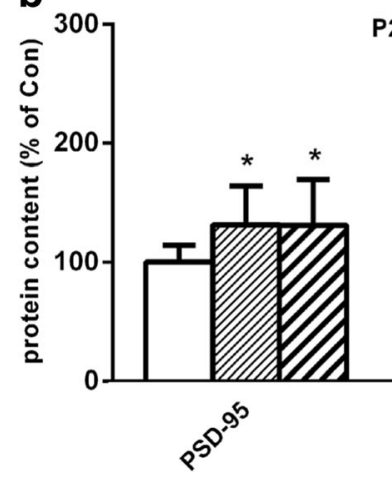

P2

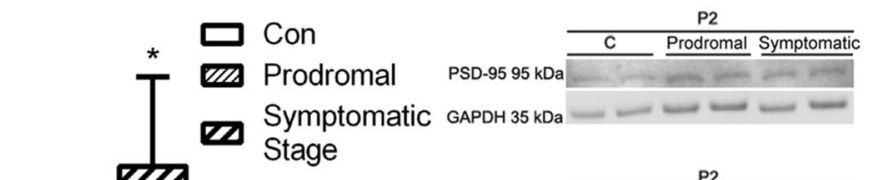
$\mathrm{C}$
$\mathrm{NR} 1130 \mathrm{kDa}=$
$\mathrm{GAPDH} 35 \mathrm{kDa}-\infty$

presynaptic terminals, the ALF-related decrease of vtila expression may therefore be considered as a likely, albeit perhaps not the only cause of the inhibition of mEPSCs.

In our study, slices from AOM-treated mice with early, minor neurological deficits and from the symptomatic animals showed impaired LTP. Impairment of LTP has been repeatedly demonstrated in chronic liver failure [4, 39], the studies mostly focusing on the role of modulation of the NMDA-sGCnNOS-NO-cGMP pathway [5, 40, 41]. The present study documents, to our knowledge for the first time, that although the expression of proteins critical for postsynaptic activity (the NR1/PSD-95/nNOS complex) was increased, LTP was nevertheless impaired. Thus, mechanisms operating beyond that complex appear to underlie the observed effect. It is conceivable that they may involve observed increase in the levels of proinflammatory cytokines, IL- 6 and TNF- $\alpha$, as activation of the cytokine network in the brain has been shown to be involved in LTP [42].

In conclusion, the here presented data demonstrate that symptomatic ALF is associated with decreased synaptic transmission which appears to be related to derangements of presynaptic proteins, resulting in inefficient sv docking to the synaptic membrane. By contrast, the content of postsynaptic proteins is enhanced, which may reflect a response to decreased presynaptic activity. Evidently, the postsynaptic modifications, occurring during symptomatic ALF, appear insufficient to provide effective compensation for the decline of LTP.
Authors' Contributions MZ/JA conceived the idea, designed the protocol, and wrote the manuscript.

$\mathrm{MP} / \mathrm{BB} / \mathrm{JS} / \mathrm{MF}-\mathrm{B} / \mathrm{RP}$ performed all the analyses for the study.

$\mathrm{RKF} / \mathrm{GH} / \mathrm{BZ}$ helped write the manuscript and intellectually refine the protocol.The authors want to give special thanks to the Small Animal Magnetic Resonance Laboratory team for help with carrying out the MRI measurements.

\section{Compliance with ethical standards}

Financial Support The research study has received funding from the Polish-Norwegian Research Program operated by the National Centre for Research and Development under the Norwegian Financial Mechanism 2009-2014 in the frame of Project Contract No. Pol-Nor/196190/23/2013 (MP, JS, BB, GH, JA, MZ). MP was additionally supported by the Leading National Research Centre (KNOW) program, and RKF was financed by the National Science Centre grant 2014/14/M/NZ4/00561. Project was carried out with the use of CePT infrastructure financed by the European Union the European Regional Development Found in the Operational Programme "Innovative Economy" for 2007-2013.

Conflict of Interest The authors declare that they have no conflict of interest.

Open Access This article is distributed under the terms of the Creative Commons Attribution 4.0 International License (http:// creativecommons.org/licenses/by/4.0/), which permits unrestricted use, distribution, and reproduction in any medium, provided you give appropriate credit to the original author(s) and the source, provide a link to the Creative Commons license, and indicate if changes were made. 


\section{References}

1. Albrecht J, Jones EA (1999) Hepatic encephalopathy: molecular mechanisms underlying the clinical syndrome. J Neurol Sci 170(2):138-146

2. Albrecht J, Zielinska M, Norenberg MD (2010) Glutamine as a mediator of ammonia neurotoxicity: a critical appraisal. Biochem Pharmacol 80(9):1303-1308. doi:10.1016/j.bcp.2010.07.024

3. Prakash R, Mullen KD (2010) Mechanisms, diagnosis and management of hepatic encephalopathy. Nat Rev Gastroenterol Hepatol 7(9):515-525. doi:10.1038/nrgastro.2010.116

4. Monfort P, Munoz MD, ElAyadi A, Kosenko E, Felipo V (2002) Effects of hyperammonemia and liver failure on glutamatergic neurotransmission. Metab Brain Dis 17(4):237-250

5. Munoz MD, Monfort P, Gaztelu JM, Felipo V (2000) Hyperammonemia impairs NMDA receptor-dependent long-term potentiation in the CA1 of rat hippocampus in vitro. Neurochem Res 25(4):437-441

6. Jayakumar AR, Tong XY, Curtis KM, Ruiz-Cordero R, Shamaladevi N, Abuzamel M, Johnstone J, Gaidosh G et al (2014) Decreased astrocytic thrombospondin-1 secretion after chronic ammonia treatment reduces the level of synaptic proteins: in vitro and in vivo studies. J Neurochem 131(3):333-347. doi:10.1111/jnc. 12810

7. Fan P, Lavoie J, Le NL, Szerb JC, Butterworth RF (1990) Neurochemical and electrophysiological studies on the inhibitory effect of ammonium ions on synaptic transmission in slices of rat hippocampus: evidence for a postsynaptic action. Neuroscience 37(2):327-334

8. Fan P, Szerb JC (1993) Effects of ammonium ions on synaptic transmission and on responses to quisqualate and N-methyl-Daspartate in hippocampal CA1 pyramidal neurons in vitro. Brain Res 632(1-2):225-231

9. Raabe W (1992) Ammonium ions abolish excitatory synaptic transmission between cerebellar neurons in primary dissociated tissue culture. J Neurophysiol 68(1):93-99

10. Raabe W, Lin S (1985) Pathophysiology of ammonia intoxication. Exp Neurol 87(3):519-532

11. Crawford DC, Kavalali ET (2015) Molecular underpinnings of synaptic vesicle pool heterogeneity. Traffic 16(4):338-364. doi:10.1111/tra.12262

12. Imig C, Min SW, Krinner S, Arancillo M, Rosenmund C, Sudhof TC, Rhee J, Brose N et al (2014) The morphological and molecular nature of synaptic vesicle priming at presynaptic active zones. Neuron 84(2):416-431. doi:10.1016/j.neuron.2014.10.009

13. Michel K, Muller JA, Oprisoreanu AM, Schoch S (2015) The presynaptic active zone: a dynamic scaffold that regulates synaptic efficacy. Exp Cell Res 335(2):157-164. doi:10.1016/j. yexcr.2015.02.011

14. Belanger M, Cote J, Butterworth RF (2006) Neurobiological characterization of an azoxymethane mouse model of acute liver failure. Neurochem Int 48(6-7):434-440. doi:10.1016/j. neuint.2005.11.022

15. Matkowskyj KA, Marrero JA, Carroll RE, Danilkovich AV, Green RM, Benya RV (1999) Azoxymethane-induced fulminant hepatic failure in $\mathrm{C} 57 \mathrm{BL} / 6 \mathrm{~J}$ mice: characterization of a new animal model. Am J Phys 277(2 Pt 1):G455-G462

16. McMillin M, Galindo C, Pae HY, Frampton G, Di Patre PL, Quinn M, Whittington E, DeMorrow S (2014) Glil activation and protection against hepatic encephalopathy is suppressed by circulating transforming growth factor beta1 in mice. J Hepatol 61(6):12601266. doi:10.1016/j.jhep.2014.07.015

17. Wen S, Schroeter A, Klocker N (2013) Synaptic plasticity in hepatic encephalopathy - a molecular perspective. Arch Biochem Biophys 536(2):183-188. doi:10.1016/j.abb.2013.04.008
18. Malenka RC, Bear MF (2004) LTP and LTD: an embarrassment of riches. Neuron 44(1):5-21. doi:10.1016/j.neuron.2004.09.012

19. Milewski K, Hilgier W, Fresko I, Polowy R, Podsiadlowska A, Zolocinska E, Grymanowska AW, Filipkowski RK et al (2016) Carnosine reduces oxidative stress and reverses attenuation of righting and postural reflexes in rats with thioacetamideinduced liver failure. Neurochem Res 41(1-2):376-384. doi:10.1007/s11064-015-1821-9

20. Crawley JN (2007) What's wrong with my mouse: behavioral phenotyping of transgenic and knockout mice. Wiley-Interscience, Hoboken, N.J

21. Corne SJ, Pickering RW, Warner BT (1963) A method for assessing the effects of drugs on the central actions of 5-hydroxytryptamine. Br J Pharmacol Chemother 20:106-120

22. Ossato A, Vigolo A, Trapella C, Seri C, Rimondo C, Serpelloni G, Marti M (2015) JWH-018 impairs sensorimotor functions in mice. Neuroscience 300:174-188. doi:10.1016/j. neuroscience.2015.05.021

23. Papadopoulos MC, Verkman AS (2005) Aquaporin-4 gene disruption in mice reduces brain swelling and mortality in pneumococcal meningitis. J Biol Chem 280(14):13906-13912. doi:10.1074/jbc. M413627200

24. Jaholkowski P, Mierzejewski P, Zatorski P, Scinska A, SienkiewiczJarosz H, Kaczmarek L, Samochowiec J, Filipkowski RK et al (2011) Increased ethanol intake and preference in cyclin D2 knockout mice. Genes Brain Behav 10(5):551-556. doi:10.1111/j.1601183X.2011.00692.x

25. Rangroo Thrane V, Thrane AS, Wang F, Cotrina ML, Smith NA, Chen M, Xu Q, Kang N et al (2013) Ammonia triggers neuronal disinhibition and seizures by impairing astrocyte potassium buffering. Nat Med 19(12):1643-1648. doi:10.1038/nm.3400

26. Cook EB, Stahl JL, Lowe L, Chen R, Morgan E, Wilson J, Varro R, Chan A et al (2001) Simultaneous measurement of six cytokines in a single sample of human tears using microparticle-based flow cytometry: allergics vs. non-allergics. J Immunol Methods 254(1-2): 109-118

27. Provencher SW (2001) Automatic quantitation of localized in vivo 1H spectra with LCModel. NMR Biomed 14(4):260-264

28. Paxinos G, Franklin KBJ (2004) The mouse brain in stereotaxic coordinates. Elsevier Academic Press

29. Zielinska M, Hilgier W, Law RO, Gorynski P, Albrecht J (1999) Effects of ammonia in vitro on endogenous taurine efflux and cell volume in rat cerebrocortical minislices: influence of inhibitors of volume-sensitive amino acid transport. Neuroscience 91(2):631638

30. Milewski K, Hilgier W, Albrecht J, Zielinska M (2015) The dimethylarginine (ADMA)/nitric oxide pathway in the brain and periphery of rats with thioacetamide-induced acute liver failure: modulation by histidine. Neurochem Int 88:26-31. doi:10.1016/j. neuint.2014.12.004

31. Zielinska M, Milewski K, Skowronska M, Gajos A, Zieminska E, Beresewicz A, Albrecht J (2015) Induction of inducible nitric oxide synthase expression in ammonia-exposed cultured astrocytes is coupled to increased arginine transport by upregulated $\mathrm{y}(+)$ LAT2 transporter. J Neurochem 135(6):1272-1281. doi:10.1111/jnc. 13387

32. Hermenegildo C, Monfort P, Felipo V (2000) Activation of Nmethyl-D-aspartate receptors in rat brain in vivo following acute ammonia intoxication: characterization by in vivo brain microdialysis. Hepatology 31(3):709-715. doi:10.1002/hep.510310322

33. Hilgier W, Olson JE (1994) Brain ion and amino acid contents during edema development in hepatic encephalopathy. J Neurochem 62(1):197-204

34. Hilgier W, Olson JE, Albrecht J (1996) Relation of taurine transport and brain edema in rats with simple hyperammonemia or liver 
failure. J Neurosci Res 45(1):69-74. doi:10.1002/(SICI)1097-4547 (19960701)45:1\&lt;69::AID-JNR6\&gt;3.0.CO;2-F

35. Gorg B, Qvartskhava N, Bidmon HJ, Palomero-Gallagher N, Kircheis G, Zilles K, Haussinger D (2010) Oxidative stress markers in the brain of patients with cirrhosis and hepatic encephalopathy. Hepatology 52(1):256-265. doi:10.1002 /hep.23656

36. Haussinger D, Schliess F (2008) Pathogenetic mechanisms of hepatic encephalopathy. Gut 57(8):1156-1165. doi:10.1136/gut.2007.122176

37. Poordad FF (2007) Review article: the burden of hepatic encephalopathy. Aliment Pharmacol Ther 25(Suppl 1):3-9. doi:10.1111/j.1746-6342.2006.03215.x

38. Carter AG, Vogt KE, Foster KA, Regehr WG (2002) Assessing the role of calcium-induced calcium release in short-term presynaptic plasticity at excitatory central synapses. J Neurosci 22(1):21-28
39. Felipo V (2013) Hepatic encephalopathy: effects of liver failure on brain function. Nat Rev Neurosci 14(12):851-858. doi:10.1038/nrn3587

40. Monfort P, Cauli O, Montoliu C, Rodrigo R, Llansola M, Piedrafita B, El Mlili N, Boix J et al (2009) Mechanisms of cognitive alterations in hyperammonemia and hepatic encephalopathy: therapeutical implications. Neurochem Int 55(1-3):106-112. doi:10.1016/j.neuint.2009.01.021

41. Monfort P, Piedrafita B, Felipo V (2009) Transport of AMPA receptors during long-term potentiation is impaired in rats with hepatic encephalopathy. Neurochem Int 55(7):514-520. doi:10.1016/j.neuint.2009.05.006

42. del Rey A, Balschun D, Wetzel W, Randolf A, Besedovsky HO (2013) A cytokine network involving brain-borne IL-1beta, IL1 ra, IL-18, IL-6, and TNFalpha operates during long-term potentiation and learning. Brain Behav Immun 33:15-23. doi:10.1016/j. bbi.2013.05.011 